\title{
Congenital intrinsic factor deficiency
}

INSERM

\section{Source}

INSERM. (1999). Orphanet: an online rare disease and orphan drug data base. Congenital intrinsic factor deficiency. ORPHA:332

Congenital intrinsic factor deficiency (IFD) is a rare disorder of vitamin B12 (cobalamin) absorption that is characterized by megaloblastic anemia and neurological abnormalities. 